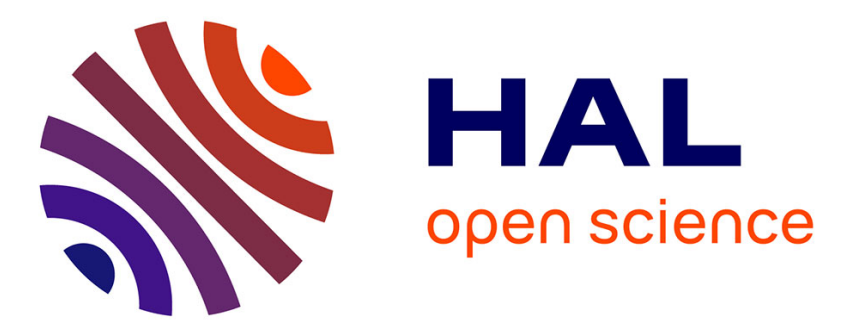

\title{
Aerobic catalytic systems inspired by copper amine oxidases: recent developments and synthetic applications
}

Martine Largeron

\section{To cite this version:}

Martine Largeron. Aerobic catalytic systems inspired by copper amine oxidases: recent developments and synthetic applications. Organic \& Biomolecular Chemistry, 2017, 15 (22), pp.4722-4730. 10.1039/c7ob00507e . hal-02384644

\section{HAL Id: hal-02384644 \\ https://hal.science/hal-02384644}

Submitted on 20 Nov 2020

HAL is a multi-disciplinary open access archive for the deposit and dissemination of scientific research documents, whether they are published or not. The documents may come from teaching and research institutions in France or abroad, or from public or private research centers.
L'archive ouverte pluridisciplinaire HAL, est destinée au dépôt et à la diffusion de documents scientifiques de niveau recherche, publiés ou non, émanant des établissements d'enseignement et de recherche français ou étrangers, des laboratoires publics ou privés. 
This article can be cited before page numbers have been issued, to do this please use: M. Largeron, Org. Biomol. Chem., 2017, DOI: 10.1039/C7OB00507E.

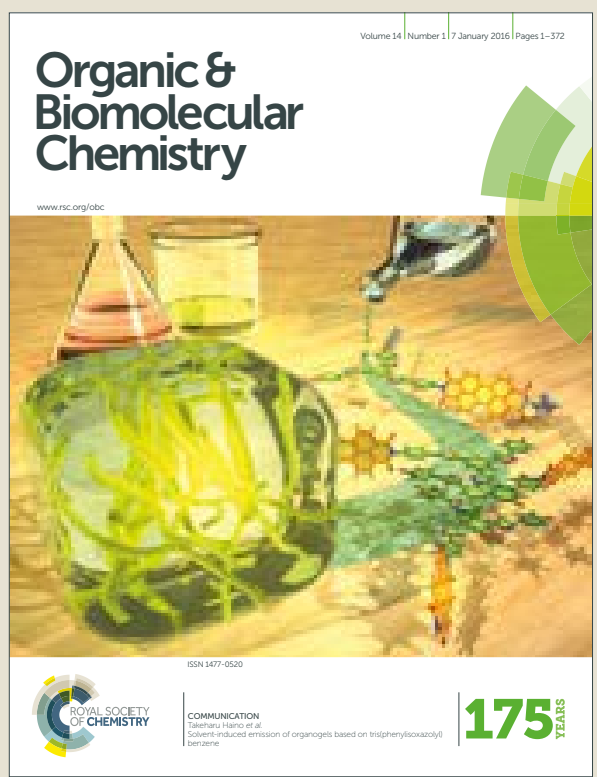

This is an Accepted Manuscript, which has been through the Royal Society of Chemistry peer review process and has been accepted for publication.

Accepted Manuscripts are published online shortly after acceptance, before technical editing, formatting and proof reading. Using this free service, authors can make their results available to the community, in citable form, before we publish the edited article. We will replace this Accepted Manuscript with the edited and formatted Advance Article as soon as it is available.

You can find more information about Accepted Manuscripts in the author guidelines.

Please note that technical editing may introduce minor changes to the text and/or graphics, which may alter content. The journal's standard Terms \& Conditions and the ethical guidelines, outlined in our author and reviewer resource centre, still apply. In no event shall the Royal Society of Chemistry be held responsible for any errors or omissions in this Accepted Manuscript or any consequences arising from the use of any information it contains. 


\section{Journal Name}

Received 00th January 20xx, Accepted 00th January 20xx

DOI: $10.1039 / \times 0 \times x 00000 x$

www.rsc.org/

\section{Aerobic catalytic systems inspired by copper amine oxidases: recent developments and synthetic applications}

\author{
Martine Largeron*a \\ Recent efforts to design synthetic quinone-based catalysts for the efficient aerobic oxidation of amines to imines have \\ been inspired by copper amine oxidases (CUAOs), a family of metalloenzymes which selectively converts primary amines \\ into aldehydes, using molecular oxygen through the cooperation of a quinone-based cofactor, 2,4,5- \\ trihydroxyphenylalanine quinone (TPQ) and a copper ion. Two distinct classes of bioinspired quinone-based catalytic \\ systems have been developed. The first class consists of catalytic systems, which mimic the activity of CuAOs by exhibiting \\ exquisite selectivity for primary amines. The second class is constituted by catalytic systems, which allow the expansion of \\ the substrate scope to the oxidation of $\alpha$-branched primary amines and secondary amines including nitrogen heterocycles, \\ two reaction types that natural CuAOs are not able to accomplish. These catalytic oxidative green processes can be applied \\ to the $\mathrm{C}-\mathrm{H}$ functionalization of primary amines and to the synthesis of several nitrogen-containing heterocycles.
}

\section{Introduction}

Copper amine oxidases (CuAOs) are ubiquitous enzymes isolated from mammals, many higher-order plants, fungi, yeasts and bacteria, which play a vital role in the physiology and pathology of mammals in controlling the metabolism of various primary monoamines, diamines and polyamines of endogenous or xenobiotic origin. ${ }^{1}$ Interest in CuAOs has greatly increased in recent years, especially since the discovery that human vascular adhesion protein-1 (VAP-1), which regulates leucocyte trafficking and glucose transport, is a CuAO enzyme. VAP-1 has been shown to be upregulated at sites of inflammation and has been implicated in human diseases such as diabetes mellitus, congestive heart failure and liver disease. ${ }^{2}$ So the rational design of selective inhibitors of CuAOs as potential therapeutic agents is of current interest. ${ }^{3}$

CuAOs catalyze the selective aerobic oxidation of primary amines to aldehydes through the synergistic action of a quinone-based cofactor, 2,4,5-trihydroxyphenylalanine quinone (TPQ), and a copper ion (Scheme 1). ${ }^{4,5} \mathrm{TPQ}$ is derived from a conserved tyrosine in a self-processing, posttranslational event that requires only copper and molecular oxygen. ${ }^{3,6}$ Through the utilization of synthetic models of TPQ cofactors, ${ }^{7}$ and using benzylamine as the model substrate, it

a. UMR 8638 CNRS-Université Paris Descartes, Sorbonne Paris Cité, Faculté de Pharmacie de Paris, 4 avenue de l'Observatoire, 75270 Paris cedex 06, France E-mail:martine.largeron@parisdescartes.fr; Tel: +33153739646; ORCID iD 0000-0002-1725-8118

+ Footnotes relating to the title and/or authors should appear here.

Electronic Supplementary Information (ESI) available: [details of any supplementary information available should be included here]. See DOI: $10.1039 / x 0 \times x 00000 x$ has been established that TPQ promotes the conversion of a primary amine into an aldehyde through a transamination process which proceeds via two half reactions (Scheme 1$):^{8}$ a reductive half reaction in which the amine substrate $\mathrm{RCH}_{2} \mathrm{NH}_{2}$ is oxidized to the aldehyde RCHO, leaving TPQ as a reduced aminoquinol form $\mathrm{TPQ}_{\mathrm{amq}}$, followed by an oxidative halfreaction which corresponds to the reduction of molecular oxygen to hydrogen peroxide, with concomitant formation of $T P Q_{i m q}$.

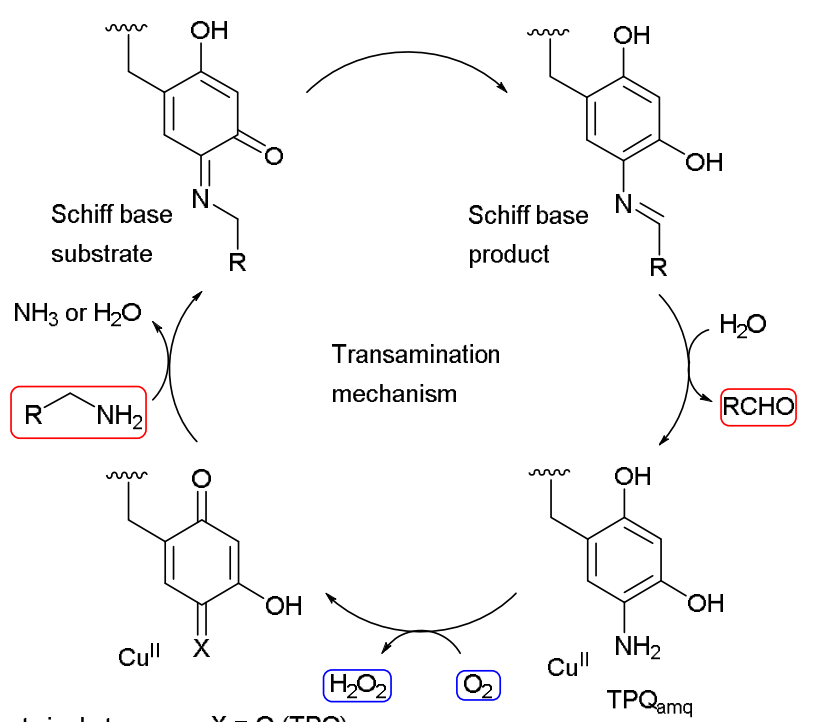

first single turnover $X=O(T P Q)$ after single turnover $\mathrm{X}=\mathrm{NH}\left(\mathrm{TPQ}_{\mathrm{mq}}\right)$

Scheme 1 Transamination mechanism followed by copper amine oxidases in vivo. 
Although the oxidation of the primary amine substrate is mediated by the quinone cofactor without direct involvement of the copper ion, this might play a role in orienting the TPQ ring correctly in the active site and in facilitating the reduction of $\mathrm{O}_{2}$ to $\mathrm{H}_{2} \mathrm{O}_{2}$. ${ }^{9}$ Very likely, the final step under single turnover conditions is a transimination reaction to form the Schiff base substrate without the need to regenerate TPQ.,8a

Whereas TPQ oxidizes a wide range of primary amines, short to long-chain aliphatic mono- and diamines including arylalkylamines, ${ }^{3}$ it fails to oxidize secondary and tertiary amines. Accordingly, 3-pyrroline derivatives have been shown to be transamination-specific mechanism-based inactivators through the formation of a stable pyrrolylated cofactor that cannot be reoxidized to the starting quinone (Scheme 2). ${ }^{10}$

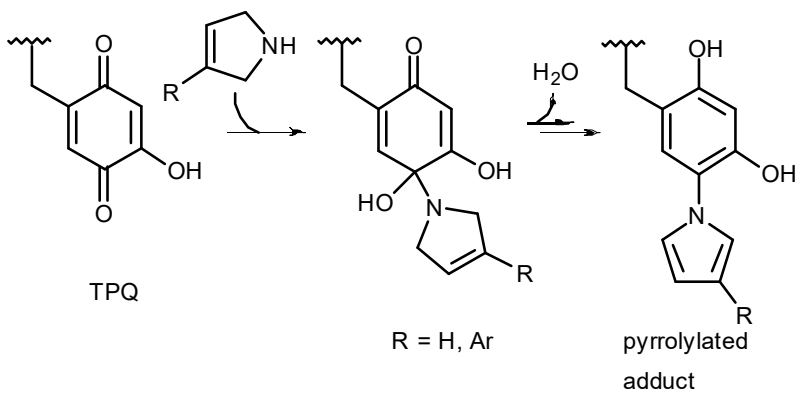

Scheme 2 Proposed pathway of CuAOs inactivation by 3 pyrroline derivatives. ${ }^{10}$

An important benefit of knowing the CuAOs mechanism is its potential application in the design of synthetic biologically inspired catalysts. The discovery of small-molecules catalysts capable of performing controlled aerobic oxidations under very mild conditions in a way reminiscent of enzyme catalysis is in constant demand by the pharmaceutical and chemical industries. $^{11}$

As a consequence, the general interest in amine oxidation chemistry $^{12}$ has stimulated efforts to discover effective quinone-based catalysts inspired by CuAOs for the aerobic oxidation of amines to imines. ${ }^{13,14}$ Imines are a very important class of compounds in chemistry that have widely been utilized as pivotal intermediates in the synthesis of fine chemicals and numerous biologically active compounds. ${ }^{15}$ Although the enzymatic transamination mechanism is not in itself a suitable path to mimic the generation of imines, in the absence of water, the Schiff base product can undergo a direct addition of the amine substrate $\mathrm{RCH}_{2} \mathrm{NH}_{2}$ leading to a dimeric imine condensation product $\mathrm{RCH}=\mathrm{NCH}_{2} \mathrm{R}$ instead of the aldehyde (Scheme 3). ${ }^{7}$ Recently, organic chemists have developed bioinspired quinone-based catalytic systems that utilize dioxygen or, more preferably, ambient air as the sole oxidant, with two objectives: a) to achieve sustainable aerobic amine oxidation reactions; b) to expand the scope of possible substrates. This paper aims to provide an overview on this area which developed rapidly during the last five years. It is organized around two classes of bioinspired quinone-based catalytic systems. The first class consists of catalytic systems, which mimic the activity of CuAOs by exhibiting exquisite selectivity for primary amines. The second class is chonstityted by catalytic systems, which allow theolexpansilonObofo5the substrate scope to the oxidation of $\alpha$-branched primary amines and secondary amines, two reaction types that natural CuAOs are not able to accomplish. The application of these green processes to the $\mathrm{C}-\mathrm{H}$ functionalization of primary amines and to the synthesis of several nitrogen-containing heterocycles is also presented.

\section{Bioinspired catalysts which exhibit the selectivity of CuAOs for primary amines}

\section{Organocatalysts}

Inspired by biochemical model studies, $^{7 b, c}$ Wendlandt and Stahl have developed a highly chemoselective method for the aerobic oxidative coupling of primary benzylic amines to yield homocoupled imines using the synthetic TPQ analog, 5-tertbutyl-2-hydroxy-1,4-benzoquinone $Q_{1}$ (Scheme 3). ${ }^{16}$ High yields of imines up to $93 \%$ were obtained, in acetonitrile, at room temperature, under 1 atm of molecular oxygen, from variously substituted benzylic amines including the heterocyclic furfurylamine. As for CuAOs, secondary amines and tertiary amines were not oxidized under the same experimental conditions. The chemoselectivity for primary amines could be easily explained by a transamination process close to that reported for natural CuAOs (Scheme 3 ). ${ }^{8}$

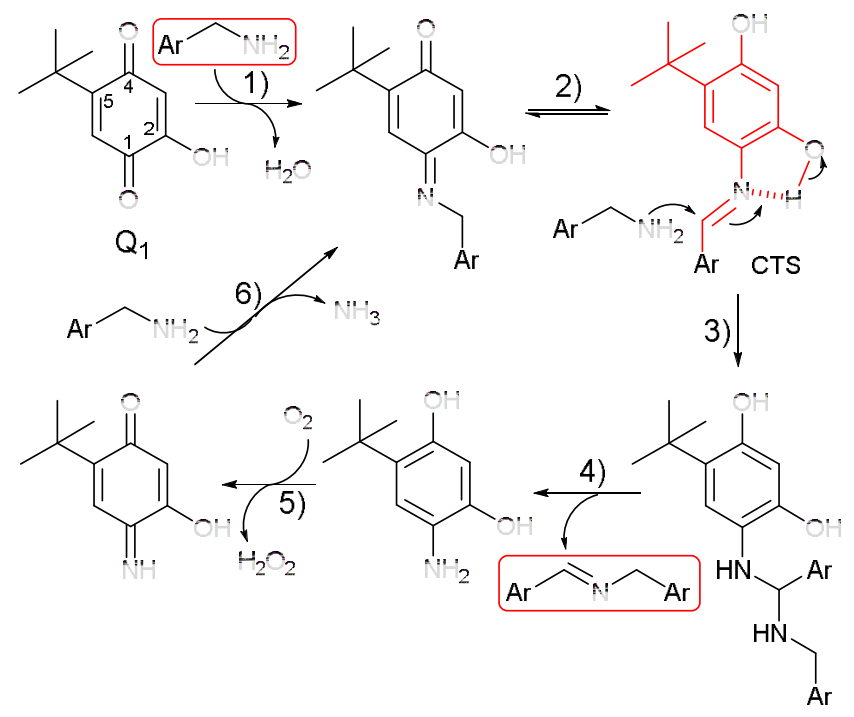

Scheme 3 Proposed ionic transamination mechanism for the aerobic oxidation of primary amines to imines catalyzed by $Q_{1}$ and other quinone-based models cofactors. ${ }^{7}$

As shown for TPQ, the presence of the hydroxyl group at the 2-position plays a crucial role in protecting the quinone ring from ring amination and in directing nucleophilic addition of amine exclusively to the C-1 position (Scheme 3, step 1). ${ }^{7 \mathrm{a}}$ Also, the activation of the imine function for further nucleophilic attack by the amine (Scheme 3, step 3), leading to the extrusion of homocoupled imine (Scheme 3, step 4), is very 
likely provided by an intramolecular hydrogen bond between the 2-hydroxy group and the imine nitrogen, generating a highly reactive cyclic transition state (CTS). ${ }^{17}$ This activated nucleophilic attack of amine, which give an aminal intermediate (Scheme 3, step 3) would constitute a driving force for the overall transamination process thereby preventing any competitive Michael addition reaction. Aerobic oxidation of the generated aminophenol form (Scheme 3, step 4) generates the iminoquinone organocatalyst (Scheme 3, step 5), which can undergo transimination with the amine substrate (Scheme 3, step 6) and close the catalytic cycle by passing $Q_{1}$. Interestingly, selective cross-coupling products could also be obtained by running the reaction in the presence of a second nonreactive primary amine. As shown in Scheme 4, primary amines bearing alcohol or amine functionalities underwent effective cross-coupling with benzylamine, without oxidation of the alcohol or amine fragment.

$$
\text { (1.5-3.0 equiv }
$$

Scheme $4 Q_{1}$-mediated aerobic cross-coupling of benzylamine with activated and non-activated primary amines.

The discovery of quinone-based catalysts has also allowed the in situ trapping of secondary imines for further reactions. Accordingly, Clift and co-workers have recently utilized the commercially available 2,6-di-tert-butyl-1,4-benzoquinone $Q_{2}$ as an organocatalyst for the preparation of $\alpha$-branched amines through a sequential quinone-promoted primary amine oxidation/nucleophilic addition process (Scheme 5). ${ }^{18}$ Like $Q_{1}$, $\mathrm{Q}_{2}$ meets some criteria essential for acting as an efficient catalyst for amine oxidation. Especially, it is sterically encumbered to prevent conjugate addition of the amine while leaving the C-4 position accessible enough to allow condensation of the amine substrate.

As in the case of TPQ cofactor and $Q_{1}, \alpha$-branched amines and secondary amines were not oxidized under the same experimental conditions. However, this oxidative $\mathrm{C}-\mathrm{H}$ functionalization protocol could be extended to allylic amines provided higher amounts of $\mathrm{Q}_{2}$ catalyst ( $20 \mathrm{~mol} \%$ ) were used.

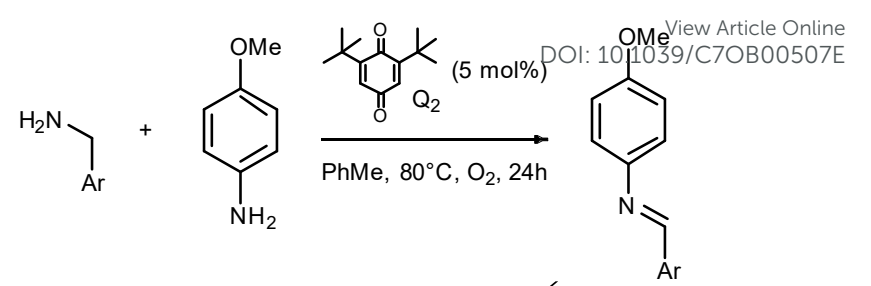

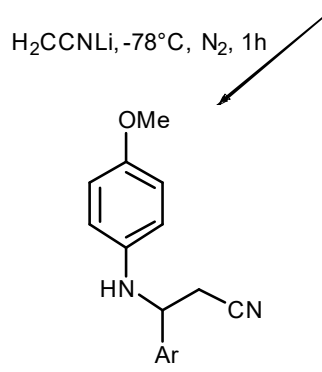

$70-90 \%$
Nuc-M, $-78^{\circ} \mathrm{C}$ , $\mathrm{N}_{2}, 1 \mathrm{~h}$<smiles>COc1ccc(NC(CN(C)C)c2ccccc2)cc1</smiles>

$71-89 \%$

Nuc $=c \operatorname{Pr}, n B u$, Me, allyl

Scheme 5 Sequential $Q_{2}$-mediated $\alpha$-functionalization of primary amines.

Finally, using simple organocatalysts, the amine substrate scope is limited to benzylic-type and allylic amines. ${ }^{7,16,18}$ The oxidation of non-activated primary alkylamines, which are natural substrates for CuAOs, ${ }^{19}$ is inherently more challenging and requires the development of cooperative catalytic sytems.

\section{Cooperative catalytic systems}

Our group has described a CuAO-like homogeneous cocatalytic system for the chemoselective oxidation of primary amines to imines at room temperature under ambient air. ${ }^{20}$ The catalytic process combines two redox couples in a way reminiscent of other biomimetic catalytic systems: ${ }^{21}$ the 0 iminoquinone organocatalyst IMQ, first discovered from electrochemical studies, $^{22}$ is the substrate-selective catalyst whereas the copper (II) salt serves as an electron-transfer mediator. The highly reactive $o$-iminoquinone organocatalyst $\mathrm{IMQ}$ is generated in situ from the corresponding 0 aminoquinol $A M Q$ which can be easily synthesized in two steps from 2-nitroresorcinol. ${ }^{23}$ The oxidation process starts with atmospheric oxygen and continues in a cascade-like manner by passing the oxidation potential of dioxygen through the copper salt $(0.2 \mathrm{~mol} \%)$ to IMQ $(2 \mathrm{~mol} \%)$, which finally oxidizes the amine substrate through a transamination mechanism analogue to that reported for natural CuAOs (Scheme 6). ${ }^{8}$ The reaction is enhanced through the participation of 1 -acetyl and 2-hydroxy substituents, as they prevent the competing formation of Michael adducts. Analogous to the hydroxy groups of TPQ and $Q_{1}$, the presence of the active 2-hydroxy substituent, which is engaged in an intramolecular hydrogen bond with the imine nitrogen to form a highly reactive Schiff base CTS, is required for the successful operation of the catalytic process. Accordingly, the analogue of $A M Q$, which lacks the 2-hydroxy substituent, generated an o-iminoquinone species which was devoid of catalytic efficiency. ${ }^{22 c}$ 


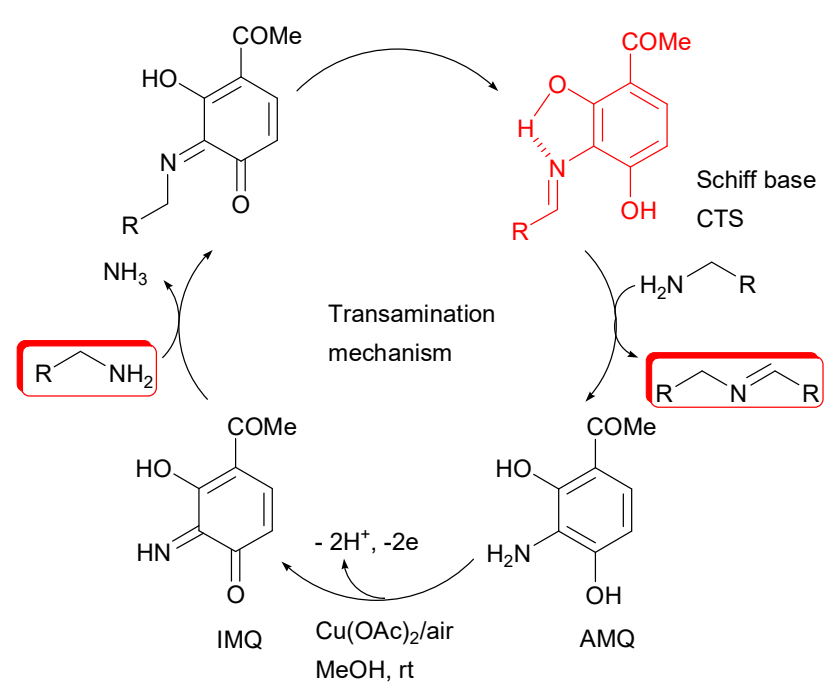

Scheme 6 Proposed ionic transamination mechanism for the $\mathrm{Cu}^{\prime \prime} / \mathrm{IMQ}$-mediated aerobic oxidation of primary amines to imines.

In the presence of a second primary aliphatic amine, functionalized cross-coupled imines could be prepared in high yields through the transamination mechanism that leads to the homocoupled imine intermediate followed by dynamic transimination (Scheme 7). As a consequence, just one equivalent of each primary amine was sufficient to achieve exclusive formation of the cross-coupled imine product. ${ }^{24}$ This oxidative strategy related to dynamic self-sorting chemistry has previously been used to obtain thermodynamically disfavoured products. ${ }^{16,25}$

Unlike simple quinone-based organocatalysts, ${ }^{7,16,18}$ IMQ was also able to oxidize non-activated primary aliphatic amines that are substrates for CuAOs enzymes. ${ }^{20,22,24}$ Note, when compared with the direct electrochemical oxidation of nonactivated primary aliphatic amines, which occurs at high anodic potential (E > $+1.5 \mathrm{~V}$ vs $\mathrm{SCE}), 1.0 \mathrm{~V}$ was gained using IMQ as the electrocatalyst. ${ }^{22 \mathrm{~d}}$ This result corroborated that, in the aerobic cooperative catalytic system $\mathrm{Cu}^{\prime \prime} / \mathrm{IMQ}$, the copper salt facilitates the aerobic oxidation of AMQ to IMQ. Although the aliphatic imines could be observed through monitoring the ${ }^{1} \mathrm{H}$ NMR spectrum, their instability and isomerisation into the enamine tautomer did not permit their isolation. ${ }^{26}$ Nevertheless, the mild reaction conditions proved to be useful for trapping the scarcely stable aliphatic imines in situ for further reactions. Through acid-free tandem oxidative DielsAlder reaction, aliphatic imines could react at room temperature as dienophile with Danishefsky's diene to form dihydro-4-pyridones $^{24}$ whereas, in the presence of $o$ aminoanilines, they were engaged in cyclocondensation reaction to furnish 1,2-disubstituted benzimidazoles, provided slightly elevated temperatures of $45-60^{\circ} \mathrm{C}$ are applied (Scheme 7). ${ }^{27}$

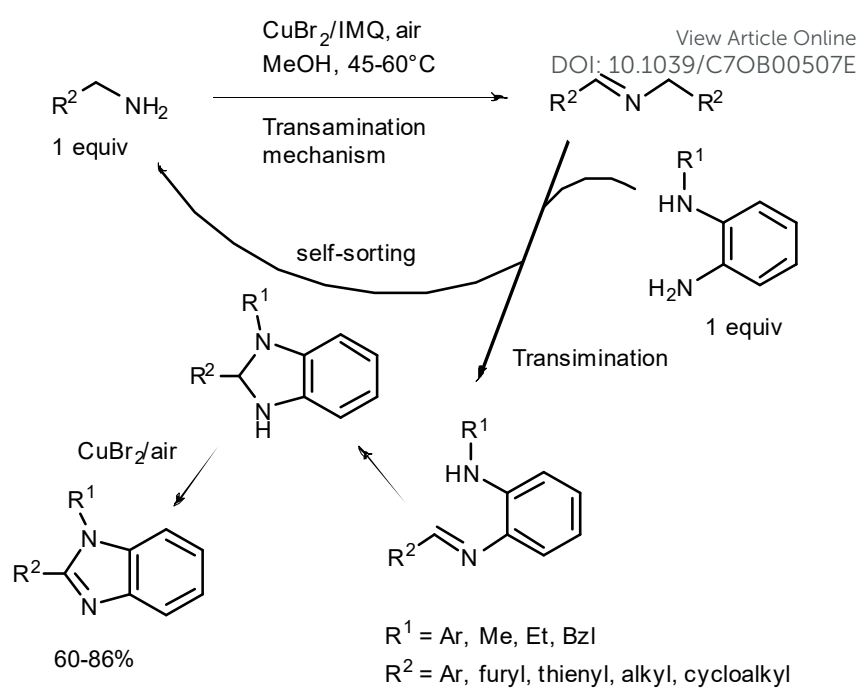

Scheme 7 Bioinspired $\mathrm{CuBr}_{2} / \mathrm{IMQ}$-mediated cascade reaction sequence leading to 1,2-disubstituted benzimidazole derivatives.

Although this cooperative catalytic system was able to work under ambient air with high atom economy and was compatible with both benzylic and non-activated primary amines, the use of a commercially available quinone-based organocatalyst would offer enhanced practicality.

Accordingly, Doris and co-workers have developed an effective heterogeneous co-catalytic system which uses commercially available 2,3,4-trihydroxyacetophenone (THAP) as a precursor of IMQ, in combination with a nanohybrid system (AuONT) made of gold nanoparticles assembled on polymerized polydiacetylene nanotubes. ${ }^{28}$ Not surprisingly, this heterogeneous cooperative catalytic system behaved like the $\mathrm{Cu}^{\prime \prime} / \mathrm{IMQ}$ homogeneous co-catalytic system and followed the same transamination mechanism (Scheme 6) at the exception of the first catalytic cycle which engaged the $o$ quinone species $Q_{3}$ generated from THAP (Scheme 8). Interestingly, AuONT co-catalyst could be recovered by centrifugation and reused five times without any loss of activity.
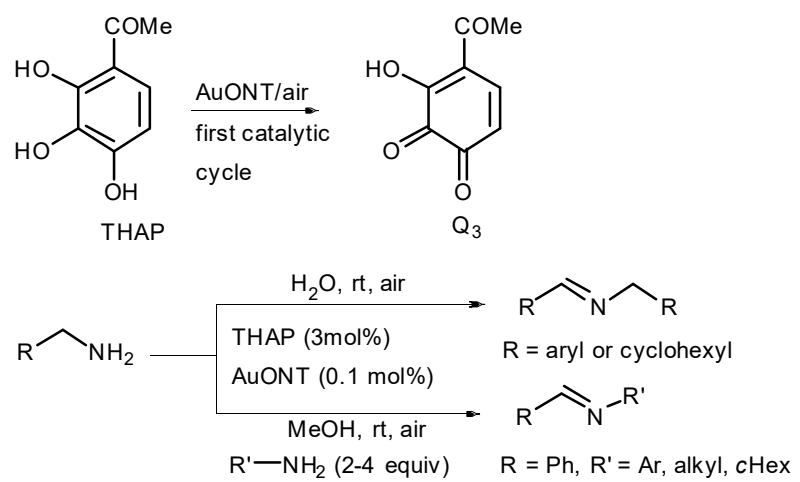

Scheme 8 Selective aerobic oxidation of primary amines mediated by the cooperative heterogeneous system AuONT/THAP. 
Recently, Carbery and co-workers have been drawn to the structure of commercially available alloxan due to the structural analogy of its tautomer with TPQ cofactor (Scheme 9). The authors demonstrated that the combination of alloxan (2.5 mol\%) and $\mathrm{CuCl}$ (1 mol\%) constituted an effective homogeneous co-catalytic system for the aerobic oxidation of primary benzylic-type amines to imines under ambient air. Provided that $5 \mathrm{~mol} \%$ of both alloxan and $\mathrm{CuCl}$ were used, selective oxidative cross-coupling of benzylamine with variously substituted anilines could be realized, while aliphatic amines were found to be poor coupling partners for similar reactions. $^{29}$<smiles>CCN1C(=O)NC(=O)C(=O)C1=O</smiles>

alloxan

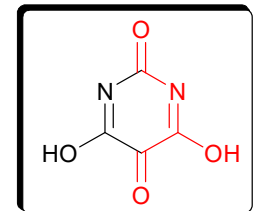

alloxan tautomer

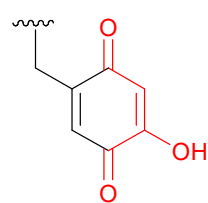

TPQ
Scheme 9 Similarity between alloxan tautomer and covalently bound quinone cofactor TPQ

Although the co-catalytic system share common features with CuAOs such as the utilization of a quinone mimetic organocatalyst together with a copper salt, mechanistic investigations revealed divergence in the reaction mechanism which adopted a radical character and does not proceed through a quinone-imine step. As a consequence, the $\mathrm{CuCl} /$ alloxan system better resembled the flavin/alloxanmediated oxidation of amines. ${ }^{30}$

The catalytic systems reported as yet for the oxidation of amines to imines have been designed to reproduce exquisite enzymatic reactivity and selectivity for primary amines. They function essentially under ambient air, which is the ideal oxidant in terms of safety and sustainability. In the meanwhile, the organic chemists have also sought to surpass the activity of CUAO enzymes by increasing the scope of amine substrates to sec-primary amines and secondary amines.

\section{Bioinspired catalysts able to expand the amine substrate scope}

\section{Organocatalysts}

Luo and co-workers have demonstrated that the 4-methoxy-5tert-butyl-o-quinone organocatalyst $\mathrm{Q}_{4}$ enables efficient aerobic oxidation, at room temperature under an $\mathrm{O}_{2}$ atmosphere, of $\alpha$-branched primary benzylic amines considered as poor substrates for CuAOs cofactors (Scheme 10). ${ }^{31}$ Through DFT studies, they pointed out that the transamination pathway, plausible only for linear primary amines in nature, could also work for the oxidation of $\alpha$ branched primary benzylic amines by $Q_{4}$. They examined the aerobic oxidation of sec-benzylamine mediated by $Q_{1}$ and $Q_{4}$.
In the presence of $Q_{1}$, the reaction was stopped at the SGhiff base substrate stage (Scheme 11) whichl: Was 3 psolatea 05 and characterized by NMR analysis.

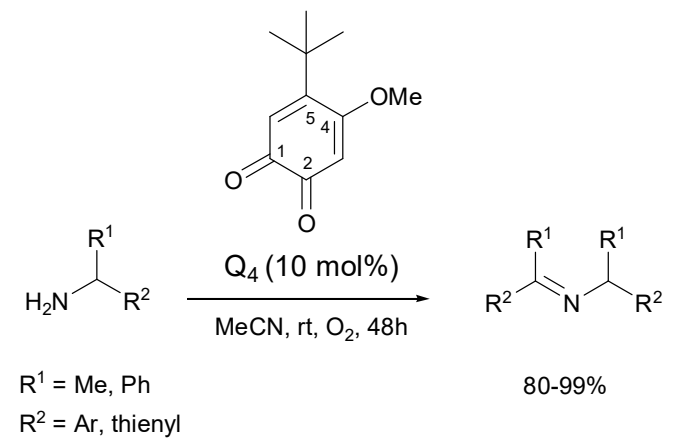

Scheme $10 \mathrm{Q}_{4}$-mediated aerobic oxidation of $\alpha$-branched primary benzylic amines.

A strong intramolecular hydrogen bond between the imine nitrogen and the hydroxy substituent was evidenced by X-ray crystallography showing the difficulty of $\mathrm{H}$-abstraction with $\mathrm{Q}_{1}$. In contrast, no similar hydrogen bond was observed in the Schiff base substrate stage of $Q_{4}$, while a weak hydrogen bond was noted between $\mathrm{C}-\mathrm{H}$ and the $\mathrm{o}$-iminoquinone oxygen facilitating $\mathrm{H}$-transfer. ${ }^{31}$ These results may account for the different performance of $p$-quinone versus $o$-quinone in the aerobic oxidation of $\alpha$-branched primary amines.

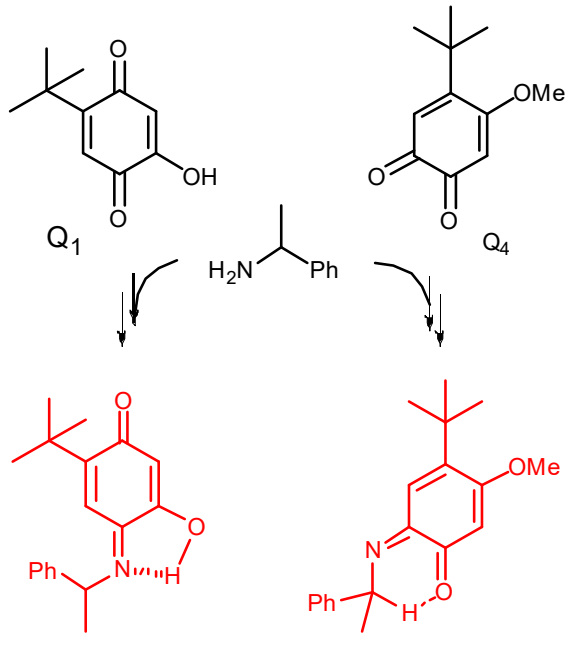

Scheme 11 Intramolecular hydrogen bond characterized by $\mathrm{X}$ ray crystallography at the Schiff base substrate stage of $Q_{1}$ and $\mathrm{Q}_{4}$.

\section{Cooperative catalytic systems}

More challenging, the possibility of expanding the scope to the oxidation of secondary amines, a reaction type that CuAOs are not able to accomplish, was extensively explored. This reaction required the development of cooperative catalytic systems including a quinone-based organocatalyst.

The group of Kobayashi was the first to report a heterogeneous nanocluster catalyst acting cooperatively with 
a quinone organocatalyst cofactor for the oxidation of secondary amines to imines under mild conditions. ${ }^{32}$ Although metal nanoclusters have been recognized as highly active catalysts for various aerobic oxidations, they had limited utility in converting amines to imines because of high temperatures required. ${ }^{33}$ The bioinspired cooperative system consists of a heterogeneous $\mathrm{Pt} / \mathrm{Ir}$ bimetallic nanocluster catalyst (0.5 mol\%) immobilized on a styrene based copolymer support, and 4tert-butyl-o-quinone $Q_{5} \quad(15-60$ mol\%) as the substrate selective organocatalyst (Scheme 12). Variously $p$-substituted dibenzylamines were converted, at $30^{\circ} \mathrm{C}$ under 1 atmosphere of $\mathrm{O}_{2}$, into the corresponding imines in high yields. In the case of 1,2,3,4-tetrahydroquinoline, a second dehydrogenation reaction occurred to produce quinoline. Note primary benzylic amines could also be oxidized to imines at the exclusion of amines bearing electron-withdrawing substituents.

Whereas the chemoselectivity of CuAOs and that of quinone-based organocatalysts $Q_{1}-Q_{4}$ and IMQ for primary amines has been readily explained through the transamination process, mechanistic investigations revealed divergence in the reaction pathways because secondary amines have been shown to be inhibitors of quinones such as $Q_{1}$ through the formation of irreversible covalent adducts. ${ }^{10,34}$ An alternative mechanism was proposed in which a quinone hemiaminal intermediate is complexed to the metal nanocluster surface and undergoes a hydride transfer process leading to the desired imine.

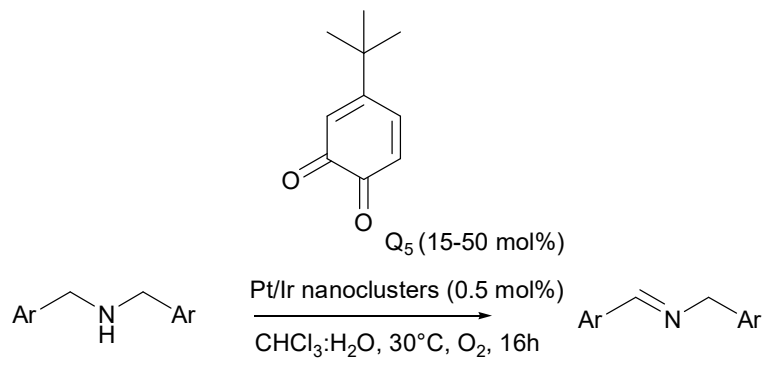

$\mathrm{Ar}=p$-substituted phenyl, 2-pyridyl<smiles>c1ccc2c(c1)CCCN2</smiles>

$$
\begin{aligned}
& \mathrm{Q}_{5}(30 \mathrm{~mol} \%) \\
& \mathrm{Pt} / \mathrm{Ir} \text { nanoclusters }(0.5 \mathrm{~mol} \%) \\
& \stackrel{\mathrm{CHCl}_{3}: \mathrm{H}_{2} \mathrm{O}, 30^{\circ} \mathrm{C}, \mathrm{O}_{2}, 16 \mathrm{~h}}{\longrightarrow}
\end{aligned}
$$<smiles>c1ccc2ncccc2c1</smiles>

$$
82 \%
$$

Scheme 12 Aerobic oxidation of secondary amines catalyzed by the $\mathrm{Pt} / \mathrm{Ir}-\mathrm{Q}_{5}$ cooperative catalytic system.

Doris and co-workers have reported a similar cooperative action of Rh nanoparticles, supported on carbon nanotubes (Rh-CNT) as co-catalyst with $\mathrm{Q}_{5}$ for the aerobic dehydrogenation, at room temperature under ambient atmosphere, of $\mathrm{N}$-heterocycles and dibenzylamine (Scheme 13). ${ }^{35}$ The reaction likely proceeds through an additionelimination pathway (Scheme 14).

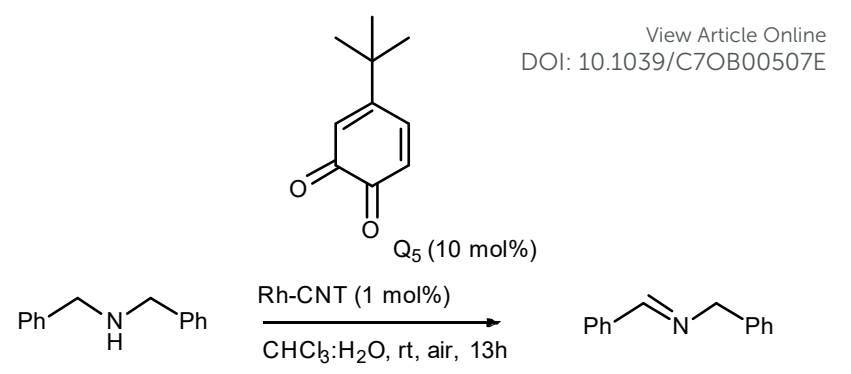

Isolated N-heterocycles<smiles>c1ccc2ncccc2c1</smiles>

$10 \mathrm{~h}, 95 \%$

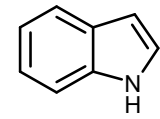

$11 \mathrm{~h}, 97 \%$

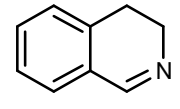

$12 \mathrm{~h}, 98 \%$<smiles>c1ccc2c(c1)[nH]c1ccccc12</smiles>

$18 \mathrm{~h}, 94 \%$<smiles>c1ccc2nc3ccccc3cc2c1</smiles>

$8 \mathrm{~h}, 98 \%$<smiles>c1ccc(-c2ncc3ccccc3n2)cc1</smiles>

$21 \mathrm{~h}, 94 \%$
Scheme 13 Aerobic dehydrogenation of secondary amines catalyzed by the Rh-CNT/ $\mathrm{Q}_{5}$ cooperative catalytic system.

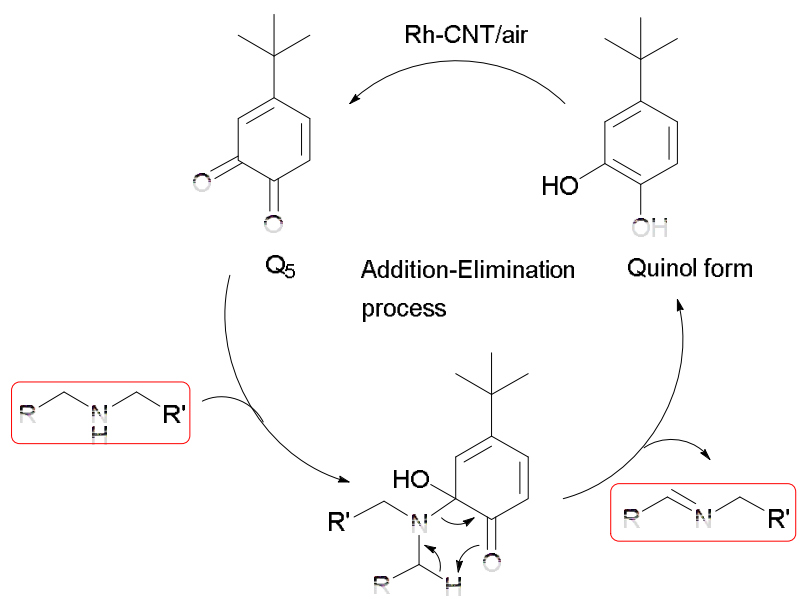

Scheme 14 Suggested addition-elimination pathway for the $\mathrm{Rh}-\mathrm{CNT} / \mathrm{Q}_{5}$-mediated aerobic dehydrogenation of secondary amines.

Wendlandt and Stahl have provided the first direct evidence for the non-biomimetic addition-elimination pathway, including observation of the hemiaminal intermediate by ${ }^{1} \mathrm{H}$ NMR spectroscopy at low temperature (Scheme 15). 
<smiles>O=C1C(=O)c2cccnc2-c2ncccc21</smiles>
$+$<smiles>c1ccc2c(c1)CCNC2</smiles>
observed at low temperature<smiles>O=C1c2cccnc2-c2ncccc2C1(O)N1CCc2ccccc2C1</smiles>

hemiaminal intermediate<smiles>[R]CNC=N[R]</smiles>

Scheme 15 Proposed addition-elimination mechanism for the $\mathrm{ZnI}_{2} / \mathrm{Q}_{6}$-mediated aerobic dehydrogenation of secondary amines and $\mathrm{N}$-heterocycles; observation of the hemiaminal intermediate by NMR spectroscopy. ${ }^{36}$

They have demonstrated that the synergistic combination of 1,10-phenanthroline-5,6-dione $\mathrm{Q}_{6}$, with $\mathrm{ZnI}_{2}$ as the cocatalyst, promotes, under atmospheric oxygen at room temperature, dehydrogenation of secondary amines and $\mathrm{N}$ heterocycles. ${ }^{36} \mathrm{Q}_{6}$ exhibits a bifunctional character resulting from the o-quinone moiety and the distal nitrogen atoms prone to coordination with metals. ${ }^{37}$ The $\mathrm{ZnI}_{2}$ co-catalyst not only enhances the amine oxidation activity, but also provides a source of iodide, which plays a critical redox role in mediating aerobic reoxidation of the reduced catalyst as shown in Scheme 15 . However, the $\mathrm{ZnI}_{2} / \mathrm{Q}_{6}$ catalytic system had some limitations as the reactions often required up to $48 \mathrm{~h}$ to reach completion and certain product classes were not easily accessible. For example, tetrahydroquinoline underwent dehydrogenation to quinoline in only $18 \%$.

Thus, improved $Q_{6}$-based catalytic systems were further elaborated to expand the amine substrate scope to tetrahydroquinolines, at room temperature with ambient air, as the terminal oxidant. Using an octahedral $\left[\mathrm{Ru}\left(\mathrm{Q}_{6}\right)_{3}\right]^{2+}$ catalyst, in combination with [Co-(salophen)] as a co-catalyst, resulted in a marked improvement of the reaction rate and led to variously substituted quinolines in high yields (Scheme 16). ${ }^{38}$

Finally, Oh and co-workers have described a cooperative catalytic system which utilizes the synthesized 4-phenyl-onaphthoquinone $Q_{7}$ whose efficiency can be modulated through the nature of the co-catalyst (Scheme 17). ${ }^{39}$ Using $\mathrm{Cu}(\mathrm{OAc})_{2}$ as the co-catalyst, the resulting system resembles the $\mathrm{Cu}(\mathrm{OAc})_{2} / \mathrm{IMQ}$ system and allows the selective aerobic oxidation of primary benzylic amines to imines. However, in contrast to the $\mathrm{Cu}(\mathrm{OAc})_{2} / \mathrm{IMQ}$ system, it failed to oxidize nonactivated primary amines. Replacing $\mathrm{Cu}(\mathrm{OAc})_{2}$ by $20 \mathrm{~mol} \%$ TFA facilitated the formation of cross-coupled imines in highckislds The mild aerobic oxidation protocol could Be fur the dehydrogenation of $\mathrm{N}$-heterocycles by changing $\mathrm{Cu}(\mathrm{OAc})_{2}$ to $\mathrm{Ag}_{2} \mathrm{CO}_{3}$.

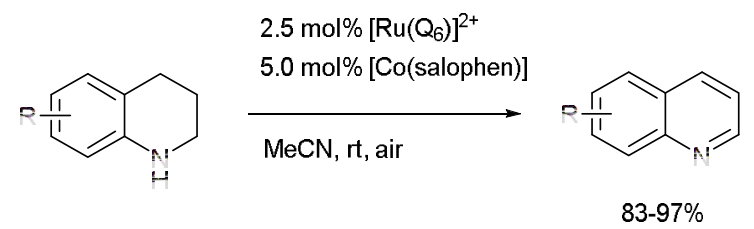

Scheme 16 Dehydrogenation of tetrahydroquinolines to quinolines with the $\left[\mathrm{Ru}\left(\mathrm{Q}_{6}\right)_{3}\right]^{2+} /[\mathrm{Co}($ salophen $)]$ cooperative catalytic system under ambient air.

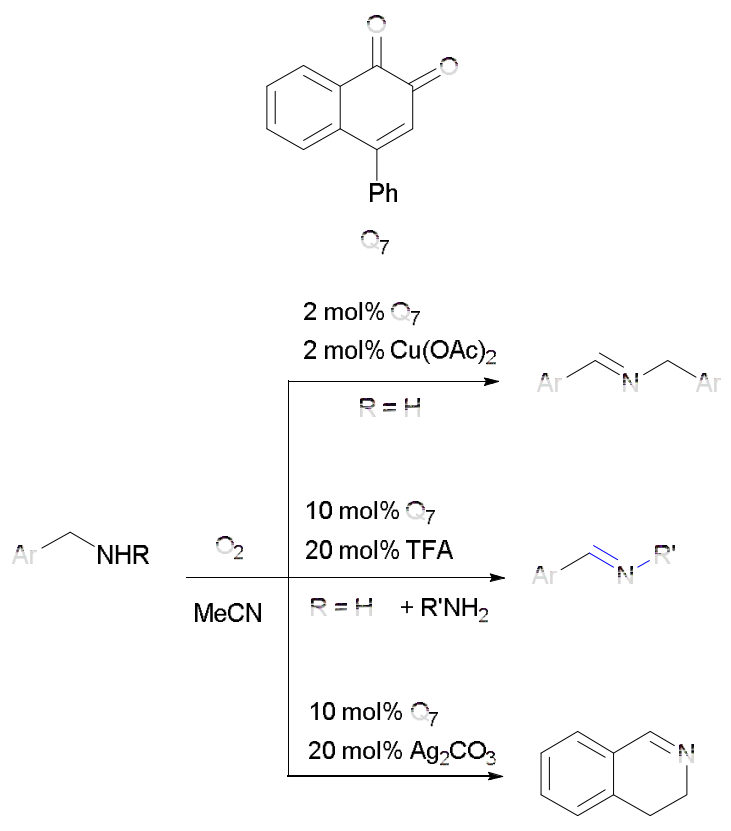

Scheme 17 Scope of $Q_{7}$-catalyzed aerobic oxidation of amines modulated by the nature of the co-catalyst.

\section{Conclusions}

The development of biomimetic methods that utilize environmentally benign oxidants such as molecular oxygen or, much better, ambient air at room temperature, and avoid deleterious side reactions, is one of the most promising goals in oxidation chemistry today.

Natural CuAO enzymes have revealed their efficiency as catalysts to perform controlled aerobic oxidation of amines under mild conditions. These enzymes couple the oxidation of primary amines to aldehydes with the reduction of $\mathrm{O}_{2}$ to $\mathrm{H}_{2} \mathrm{O}_{2}$, through the synergistic action of a quinone-based cofactor TPQ and a copper ion.

Recently, there has been a boost in the development of various catalytic methods for the aerobic oxidation of amines to imines given the widespread importance of imines as 
pivotal synthetic intermediates in a plethora of reactions such as reductions, additions, condensations and cycloadditions. Imines also serve as essential pharmacophores in numerous biologically active compounds.

During the last five years, researchers have begun to realize that $\mathrm{CuAOs}$ could constitute a rich source of inspiration for the rational design of small-molecules catalysts for the oxidation of amines to imines. Two approaches have been then envisaged.

The first approach consists of the design of biomimetic quinone-based catalytic processes, allowing to reproduce the enzymatic reactivity and selectivity for primary amines. These sytems generally function under ambient air, at room temperature and follow a transamination mechanism reminiscent of that reported for natural CuAOs. However, organocatalysts are exclusively active on benzylic amines and the discovery of more reactive quinone species able to oxidize non-activated primary aliphatic amines, which are substrates for CuAOs, remains a challenge. Through the cooperative action of a metal ion as a redox mediator, the sole $\mathrm{Cu}^{\prime \prime} / \mathrm{IMQ}$ system was sufficiently reactive to oxidize non-activated primary amines because it closely resembles the enzymatic system.

In a second approach organic chemists have sought to surpass the activity of CuAO enzymes by increasing the scope of amine substrates. They have designed organocatalysts and cooperative catalytic systems for the oxidation of $\alpha$-branchedprimary amines and secondary amines, two reaction types that natural CuAOs are not able to accomplish. In the case of the oxidation of secondary amines, a shift from the transamination path to the addition-elimination mechanism was clearly demonstrated through the characterization of an hemiaminal intermediate. Finally, the utilization of biocompatible rather than rare and precious metals as co-catalyst should allow the development of new improved sustainable catalytic systems.

\section{Acknowledgements}

The author would like to thank CNRS and Paris Descartes University for financial support. Co-workers and students listed in references $13,20,22-24$ and 27 are gratefully acknowledged for their research contributions.

\section{Notes and references}

1 For reviews, see: (a) J. P. Klinman, Chem. Rev. 1996, 96, 2541; (b) J. P. Klinman, Biochim. Biophys. Acta, 2003, 1647, 131; (c) B. J. Brazeau, B. J. Johnson and C. M. Wilmot, Arch. Biochem. Biophys., 2004, 428, 22; (d) P. Matyus, B. Dajka-Halasz, A. Földi, N. Haider, D. Barlocco, K. Magyar, Curr. Med. Chem. 2004, 11 1285; (e) M. Strolin Benedetti, K. F. Tipton and R. Whomsley, Fondam. Clin. Pharmacol., 2007, 21, 467; (f) A. Boobis, J. B. Watelet, R. Whomsley, M. Strolin Benedetti, P. Demoly and K. T. Tipton, Drug Metab. Rev., 2009, 41, 486.
2 For reviews, see: (a) P. Dunkel, A. Gelain, D. Barlocco, N. Haider, K. Gyires, B. Sperlagh, K. Magyar, E. Maccoioni,1A3 Ffacddas and P. Matyus, Curr. Med. Chem., 2008, 15, 1827; (b) F. Yraola, A. Zorzano, F. Alberricio and M. Royo, ChemMedChem, 2009, 4, 495; (c) S. Kaitaneimi, H. Elovaara, K. Grön, H. Kidron, J. Liukkonen, T. Salminen, M. Salmi, S. Jalkanen and K. Elima, Cell. Mol. Life Sci., 2009, 66, 2743.

3 For a recent review, see: E. M. Shepard and D. M. Dooley, Acc. Chem. Res. 2015, 48, 1218.

4 S. Suzuki, T. Okajima, K. Tanizawa and M. Mure, Cofactors of amine oxidases. Copper ion and its substitution and the 2,4,5-trihydroxyphenylalanine quinone. In Copper Amine Oxidases. Structures, Catalytic Mechanisms, and Role in Pathophysiology, ed. G. Floris and B. Mondovi, CRC Press, Taylor and Francis Group Publishing, New York, 2009; pp 19.

5 S. M. Janes, D. Mu, D. Wemmer, A. J. Smith, S. Kaur, D. Maltby A. L. Burlingame and J. P. Klinman, Science, 1990, 248, 981.

6 For a recent review, see: J. P. Klinman and F. Bonnot, Chem. Rev. 2014, 114, 4343.

7 For selected examples, see: (a) Y. Lee and L. M. Sayre, J. Am. Chem. Soc., 1995, 117, 3096; (b) M. Mure and J. P. Klinman, J. Am. Chem. Soc., 1995, 117, 8698; (c) M. Mure and J. P. Klinman, J. Am. Chem. Soc., 1995, 117, 8707; (d) Y. Lee and L. M. Sayre, J. Am. Chem. Soc., 1995, 117, 11823; (e) K. Q. Ling, J. Kim and L. M. Sayre, J. Am. Chem. Soc., 2001, 123, 9606; (f) M. Mure, S. X. Wang and J. P. Klinman, J. Am. Chem. Soc., 2003, 125, 6113.

8 (a) M. Mure S. A. Mills and J. P. Klinman, Biochemistry, 2002, 41 9269-9278; (b) M. Mure, Acc. Chem. Res., 2004, 37, 131; (c) J. L. DuBois and J. P. Klinman, Arch. Biochem. Biophys., 2005, 433, 255.

9 B. Schwartz, A. K. Olgin and J. P. Klinman, Biochemistry, 2001 40, 2954.

10 Y. Zhang, C. Ran, G. Zhou and L. M. Sayre, Bioorg. Med. Chem. 2007, 15, 1868.

11 L. Que Jr and W. B. Tolman, Nature, 2008, 455, 333.

12 For a recent review, see: M. T. Schümperli, C. Hammond and I. Hermans, ACS Catal. 2012, 2, 1108.

13 M. Largeron and M.-B. Fleury, Science, 2013, 339, 43

14 For a comprehensive review on quinone-catalyzed selective oxidation of organic molecules, see: A. E. Wendlandt and S. S. Stahl, Angew. Chem. Int. Ed. 2015, 54, 14638.

15 For reviews, see: (a) J. P. Adams, J. Chem. Soc. Perkin Trans 1 2000, 2, 125; (b) R. D. Patil and S. Adimurthy, Asian J. Org. Chem. 2013, 2, 726; (c) M. Largeron, Eur. J. Org. Chem. 2013, 5225; (d) B. Chen, L. Wang, S. Gao, ACS catal. 2015, 5, 5851.

16 A. E. Wendlandt and S. S. Stahl, Org. Lett. 2012, 14, 2850.

17 Similar effects of a 2-phenolic hydroxyl group on the reactivity of ketimine have been previously reported in the literature. See for example: (a) H. Miyabe, Y. Yamaoka and Y. Takemoto, Synlett, 2004, 2597; (b) H. Miyabe, Y. Yamaoka and Y. Takemoto, J. Org. Chem. 2006, 71, 2099.

18 M. A. Leon, X. Liu, J. H. Phan and M. D. Clift, Eur. J. Org. Chem. 2016, 4508

19 (a) V. J. Klema, C. J. Sohleid, J. P. Klinman and C. M. Vilmot, Biochemistry, 2013, 52, 2291; (b) P. Tavladoraki, A. Cona and R. Angelini, Front. Plant. Sci. 2016, 7, doi: 10.3389/fpls.2016.00824.

20 M. Largeron and M.-B. Fleury, Angew. Chem. Int. Ed. 2012, 51, 5409.

21 J. Piera and J. E. Bäckvall, Angew. Chem. Int. Ed. 2008, 47 3506.

22 (a) M. Largeron and M.-B. Fleury, J. Org. Chem., 2000, 65, 8874; (b) M. Largeron, A. Neudörffer and M.-B. Fleury, Angew. Chem. Int. Ed., 2003, 42, 1026; (c) M. Largeron, A. Chiaroni and M.-B. Fleury, Chem.-Eur. J., 2008, 14, 996; (d) M. Largeron, M.-B. Fleury and M. Strolin Benedetti, ECS Trans. 2010, 25, 97; (e) M. Largeron, M.-B. Fleury and M. Strolin Benedetti, Org. Biomol. Chem. 2010, 8, 3706. 


\section{Journal Name}

23 D. Xu, A. Chiaroni, M.-B. Fleury and M. Largeron, J. Org. Chem. 2006, 71, 6374.

24 M. Largeron and M.-B. Fleury, Chem.-Eur. J., 2015, 21, 3815.

25 For a review, see: M. E. Belowich, J. F. Stoddart, Chem. Soc. Rev. 2012, 41, 2003.

26 D. B. Ushakov, M. B. Plutschack, K. Gilmore and P. H. Seeberger, Chem.-Eur. J., 2015, 21, 6528.

27 (a) K. M. H. Nguyen and M. Largeron, Chem.-Eur. J., 2015, 21, 12606; (b) K. M. H. Nguyen and M. Largeron, Eur. J. Org. Chem. 2016, 1025.

28 D. V. Jawale, E. Gravel, E. Villemin, N. Shah, V. Geersten, I. N. N. Namboothiri and E. Doris, Chem. Commun. 2014, 50, 15251.

29 A. T. Murray, R. King, J. V. G. Donnelly, M. J. H. Dowley, F. Tuna, D. Sells, M. P. John and D. R. Carbery, ChemCatChem 2016, 8, 510.

30 A. T. Murray, M. J. H. Dowley, F. Pradaux-Caggiano, A Baldansuren, A. J. Fielding, F. Tuna, C. H. Hendon, A. Walsh, G. C. Lloyd-Jones, M. P. John and D. R. Carbery, Angew. Chem. Int. Ed. 2015, 54, 8997.

31 Y. Qin, L. Zhang, J. Lv, S. Luo and J.-P. Cheng, Org. Lett. 2015, $17,1469$.

32 H. Yuan, W.-J. Yoo, H. Miyamura and S. Kobayashi, J. Am. Chem. Soc. 2012, 134, 13970.

33 R. Akiyama and S. Kobayashi, Chem. Rev. 2009, 109, 594.

34 (a) Y. Lee, H. Huang and L. M. Sayre, J. Am. Chem. Soc. 1996, 118, 7241; (b) Y. Lee, K.-Q. Ling, X. Lu, R.B. Silverman, E. M. Shepard, D. M. Dooley and L. M. Sayre, J. Am. Chem. Soc. 2002, 124, 12135.

35 D. V. Jawale, E. Gravel, N. Shah, V. Dauvois, H. Li, I. N. N. Namboothiri and E. Doris, Chem. -Eur. J. 2015, 21, 7039.

36 A. E. Wendlandt and S. S. Stahl, J. Am. Chem. Soc. 2014, 136, 506.

37 C. A. Goss, H. D. Abruna, Inorg. Chem. 1985, 24, 4263.

38 A. E. Wendlandt and S. S. Stahl, J. Am. Chem. Soc. 2014, 136, 11910.

39 Y. Goriya, H. Y. Kim and K. Oh, Org. Lett. 2016, 18, 5174. 